\title{
The built environment and obesity
}

\author{
You are where you live
}

\section{Ivan Parise}

\section{Background}

Obesity has continued to rise in prevalence globally. Its association with many chronic diseases is posing a large threat to public health.

\section{Objective}

The aim of this article is to examine briefly the nature and complexity of the problem of obesity and to present evidence about the elements of the built environment that are associated with obesity.

\section{Discussion}

Management of obesity is far more complex than just requiring people to 'eat less and exercise more'. Social and environmental drivers are known to influence an individual's decisions about healthy behaviour. Some elements of the built environment shown to be associated with obesity are urban sprawl, urban design, land-use mix, transport systems, access to and type of food outlets, and building design. This evidence augments the current individual clinical management of obesity by providing guidance to advocates of health and regulators so they are able to design and create environments that foster healthy eating and personal activity.
HIGH BODY MASS INDEX (BMI; $\geq 25 \mathrm{~kg} / \mathrm{m}^{2}$ ) is now a problem in every country, ${ }^{1}$ and the prevalence of high BMI in Australia is one of the highest in developed nations. ${ }^{2}$ In $2017-18,67.0 \%$ of Australian adults (12.5 million people) had a high BMI, and $31.3 \%$ (5.8 million people) were obese $\left(\mathrm{BMI} \geq 30 \mathrm{~kg} / \mathrm{m}^{2}\right){ }^{3}$ This is a substantial increase from 1995 , when only $56.3 \%$ of Australians had a high $\mathrm{BMI}$, and represents a trend that is global and growing. ${ }^{3}$

In 2016, high BMI was estimated to be responsible for over $8 \%$ of deaths in the world and nearly $6 \%$ of the total disability adjusted life years (DALYs) lost. High BMI was ranked the third-highest risk factor in Australia for all-cause mortality ( 75 out of 100,000) and the highest risk factor for overall burden of disease, responsible for approximately $8 \%$ of the total DALYs lost. ${ }^{1}$

It is time for the discourse about obesity in clinical medicine to be broadened and informed by emerging evidence of the environmental determinants that affect obesity. Given the aforementioned statistics, relying on the formula of 'eat less and do more exercise', although it has some merit when treating obesity in the individual, has not halted the emerging crisis of obesity in modern human populations.

Additionally, the current largely individualistic approach represented in the media, research and clinical interventions has contributed to 'weight stigma' - the personal responsibility people feel for their being overweight. This is amplified by weight stereotypes and social attitudes that frame obesity as a 'personal failure'4 and only serve to increase the stress on people who are overweight, thus risking further weight gain and harm to their health. ${ }^{5}$ Unfortunately, this stress is augmented by negative bias that has also been shown by some health professionals when treating people who are overweight. ${ }^{5-8}$

It is not possible to explain the sharp and continued rise in obesity throughout the world purely on individual grounds, whether genetic or behavioural. ${ }^{9}$ Obesity is a much more complex problem that extends far beyond individual choice, and is affected by multiple interrelated influences: social, such as level of education, employment and income; ${ }^{10}$ and environmental, such as the design of residential environments and the impact this has on access to healthy food and ability to be physically active. ${ }^{11}$

This complexity can be shown using a spray diagram, as is used in systems theory (Figure 1). Rather than a 'simple' personal behaviour (eg 'eat less and exercise more'), this diagram shows multiple elements that interact to affect the epidemiology of obesity. Many of these forces are outside the direct control of individuals yet are critical to promoting healthy communities.

The importance of recognising 'upstream' factors to public health issues was well demonstrated by the history of tobacco smoking. Interventions outside 
the individual's direct control - such as restriction of access to cigarettes, increased cost and regulations decreasing smoking in public spaces - played a vital part in decreasing smoking rates in Australia. ${ }^{12}$

The approach to obesity is slowly evolving in a similar way. Interventions including raising sugar taxes, improving nutrition in schools and reducing advertisements and exposure to high-calorie foods, especially for minors, is starting to be increasingly discussed and implemented. However, an area that requires more attention is that of the environment, especially the built environment - the environment constructed by humans as opposed to occurring naturally. The built environment is where nearly all humans live, work, play, eat and exercise. It includes housing, means of transport, worksites, schools, retail centres and recreation areas that are part of the large rural and urban networks around the globe.

\section{'Obesogenic environments': What is the evidence?}

Research investigating the association between indices of the built environment and health is still in its early stages, with most being published since the start of this century. As part of this research, there has been accumulating evidence showing an association between obesity and the built environment. ${ }^{13-16}$ The term 'obesogenic environments' was coined as a result of this association. It is a somewhat misleading term, because the environment does not directly cause obesity as much as it provides the conditions encouraging weight gain - 'most people will struggle to alter their behaviour in environments that promote high energy intake and physical inactivity'. ${ }^{9}$

One of the earliest associations of a measure of the built environment and obesity was reported by Ewing et al in the USA in 2003. After controlling for demographic and behavioural confounders, a measure of urban sprawl was found to have a significant association with obesity $(P<0.001)$, as well as BMI $(P=0.005)$, minutes walked $(P=0.001)$ and hypertension $(P=0.018) .{ }^{17}$ The association with obesity was reproduced in many other studies that used population density as the measure to determine urban sprawl. ${ }^{18-24}$

Ongoing research aims to understand the reasons why urban sprawl is correlated with obesity. Data suggest that longer times spent travelling to work are negatively associated with healthy behaviour in general, ${ }^{25-30}$ possibly because of a trade-off between the time spent travelling and the time spent on healthy behaviour (eg cooking whole food and exercising).$^{29}$ This is supported by a cohort study from Adelaide showing that the distance of one's residence from the city centre was associated with abdominal circumference. Participants living $\geq 20 \mathrm{~km}$ from the city centre had a mean abdominal circumference increase of $2.4 \mathrm{~cm}$ over four years, in comparison to $1.2 \mathrm{~cm}$ for participants who lived $\leq 9 \mathrm{~km}$ away from the city centre. ${ }^{31}$ Other research has suggested that commuting time is a possible link between urban sprawl and obesity. ${ }^{32-38}$

Low-density development means that desired destinations (eg work, schools, shopping centres and transit stations) are further away from residences, and therefore are associated with greater use of cars. Wen et al concluded that driving to work was associated with an increased risk (adjusted odds ratio $=1.13 ; P=0.047$ ) of having a high BMI. ${ }^{34}$ Car use is generally associated with less physical activity, ${ }^{39}$ and the risk of obesity has been estimated to increase by $6 \%$ for each hour spent in a car daily. ${ }^{22}$ Conversely, using public transport has been negatively associated with obesity. ${ }^{40,41}$ There was a mean decrease in BMI of $0.3 \mathrm{~kg} / \mathrm{m}^{2}$ (95\% confidence interval: $-0.47,-0.13 ; P=0.0005)$ for people who changed from car commuting at baseline to active transport (bicycle/ walking) or public transportation in a prospective study of over 20,000 commuters in the UK. ${ }^{37}$

As well as low-density development, other elements of urban design have been associated with obesity, such as town planning that discourages activity. ${ }^{22}$ A scarcity of green spaces (parks and trails), lack of footpaths, poor cycling infrastructure, low numbers of safe crossings, poor land-use mix that inhibits residents from walking to shops/schools/ work, and building and school design that discourages the use of stairs and walking have all been found to be associated with obesity. ${ }^{42-44}$

An important sector of the built environment is the workplace. High BMI steadily rises in the working age group, especially in men, peaking at the age of 65 years. ${ }^{45}$ Decreased time for healthy behaviour because of commuting, an increase in sedentary jobs and the rise of labour-saving technology have all contributed to decreased activity and high BMI in this population. ${ }^{9,42}$ Additionally, features of the work environment have been suggested to affect physical activity, for example: stair access, connectivity between buildings and shelter from the elements, parking situation and availability of amenities such as gym/gym membership. ${ }^{42}$ Because of the time-poor nature of the working population, there is a scarcity of research into the workplace environment and obesity. ${ }^{46}$

Finally, 'food security', or reliable access to affordable healthy, fresh food, is important for maintaining healthy weight. Food security can vary according to area; for example, the cost of fresh food has been found to be greater in remote areas and neighbourhoods with fewer economic resources. ${ }^{47,48}$ The density and hence proximity of food outlets to homes, work and schools can affect the choice of food sourced and can vary according to area. In general, neighbourhoods of fewer economic resources have a higher density of smaller convenience stores and fast-food outlets, which have been associated with increased BMI. ${ }^{47,49}$ A study in the USA reported that a one standard deviation increase in the density of fast-food outlets was associated with a $7 \%$ increase in overweight/obesity. ${ }^{50}$

\section{Conclusion}

The large body of evidence, summarised in Table 1, is compelling and must be included in any public health strategy to tackle obesity. In the clinical setting, the evidence assists to develop a more holistic 


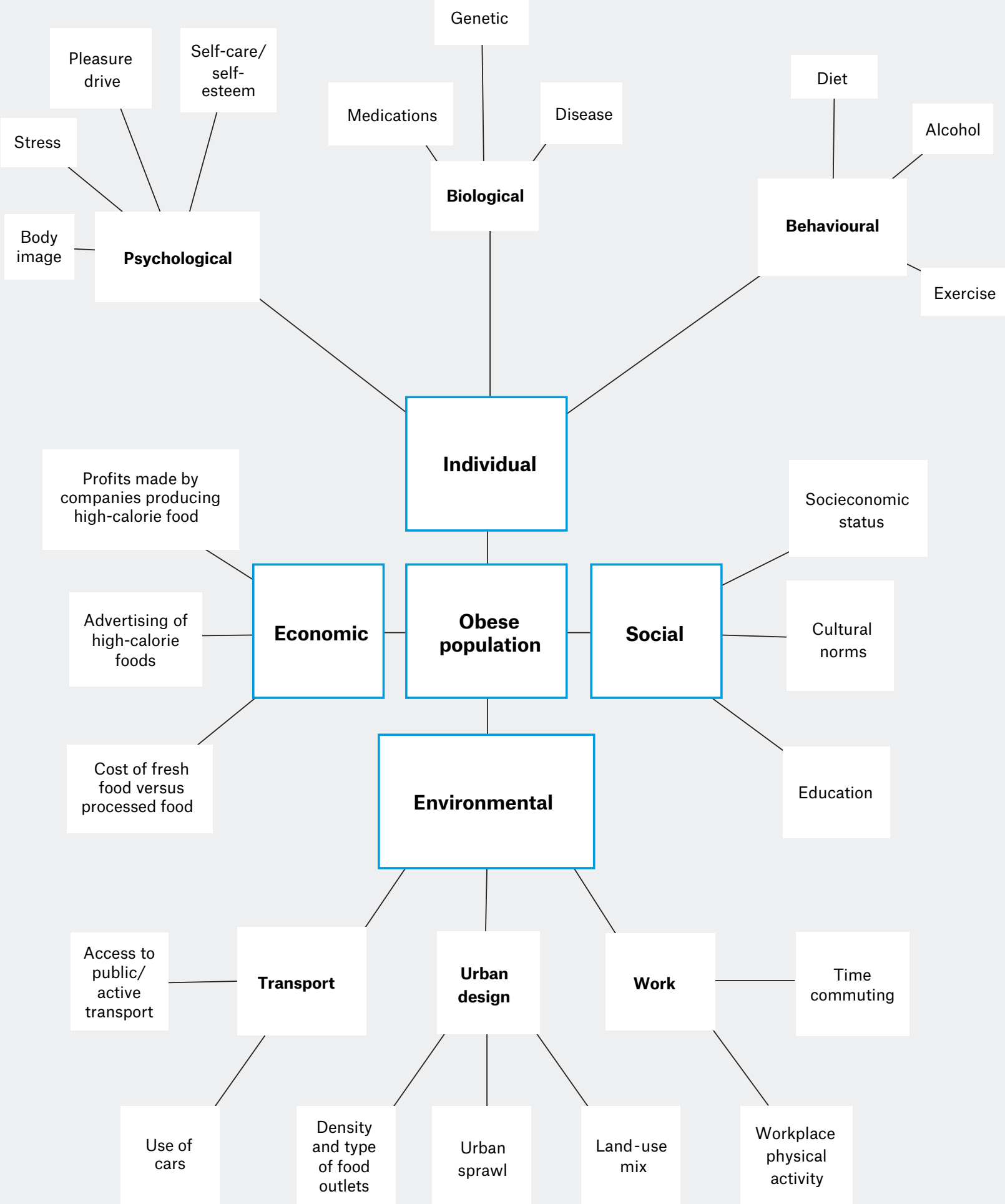

Figure 1. Spray diagram demonstrating elements connected in a system that facilitates obesity in populations 
understanding of the difficulties that a person faces to achieve a healthy weight. This will decrease the guilt and stress of being overweight, improve rapport and potentiate the development of specific strategies such as using public transport or active transport where possible.

As with most social and environmental drivers, general practitioners (GPs) can have a vital role in advocating for the health of patients, through participating in health research that informs the development of built environments. Among the many examples are the Ingham Institute for Applied Medical Research in Liverpool, New South Wales, which launched the Urban Incubator in 2018; and the RMIT University for Urban Research in Melbourne, Victoria. These insitutes provide platforms for researchers to disseminate public health evidence and to engage with landscape architects, health district executives, councils and the community to evaluate health and wellbeing aspects of developments.

Community groups are also opportunities for GPs to advocate for healthier environments; 'Healthy Cities Illawarra' is one example that has grown out of the World Health Organization's 'Healthy Cities' movement. Finally, professional bodies such as the Australian Medical Association, The Royal Australian College of General Practitioners, Doctors Reform Society, Rural Doctors Association and Doctors for the Environment are well placed to develop position statements and media releases, and lobby for healthy built environments.

\section{Table 1. Elements of the built environment associated with weight gain}

\begin{tabular}{|c|c|}
\hline Sector of built environment & Factors thought to affect weight gain \\
\hline City growth & $\begin{array}{l}\text { Urban sprawl: } \\
\text { - more time commuting } \\
\text { - greater use of cars } \\
\text { - less active commuting (walking/bicycle) }\end{array}$ \\
\hline Transport & $\begin{array}{l}\text { Adequacy of public transport service: } \\
\text { - number and affordability of trains/buses } \\
\text { - distance to public transport stations } \\
\text { - destination accessibility } \\
\text { - facilities for bicycles }\end{array}$ \\
\hline Neighbourhood infrastructure & $\begin{array}{l}\text { Town planning: } \\
\text { - amount of green space } \\
\text { - footpaths } \\
\text { - street connectivity } \\
\text { - cycling infrastructure } \\
\text { - safe crossings }\end{array}$ \\
\hline Land use & $\begin{array}{l}\text { Land-use mix: } \\
\text { greater variety (education, shops, employment, } \\
\text { residence) in one area encourages walking to access } \\
\text { destination instead of driving }\end{array}$ \\
\hline Food environment & $\begin{array}{l}\text { Density of convenience stores } \\
\text { Density of fast-food outlets } \\
\text { Affordable fresh-food outlets }\end{array}$ \\
\hline Work/education place & $\begin{array}{l}\text { Sites that encourage walking: } \\
\text { - close to public transport } \\
\text { - stairs } \\
\text { - covered walkways } \\
\text { Dedicated areas for exercise: } \\
\text { - gymnasium }\end{array}$ \\
\hline
\end{tabular}

The way we build our cities, towns and rural environments affects our health. Our ability to access healthy food and participate in physical activity is contextual to the built environment. Unplanned and unsupported growth of cities means that populations who are already at risk of obesity, by having fewer economic resources, are pressured to find residences further away from centres of employment. They therefore rely more on cars and have less time to participate in healthy behaviour, thus increasing their risk of obesity and chronic disease. To help our patients, it is a matter of urgency that we move beyond our current approach. Increasing knowledge or advice on losing weight is not enough if the individual does not have enough time, money or resources to change to a healthier behaviour.

\section{Author}

Ivan Parise MBBS, DRACOG, Dip Shared Care Psychiatry (Eating Disorders), MPHTM, Conjoint Senior Lecturer, School of Medicine, Western Sydney University, NSW; Honorary Associate, The School of Public Health, The Faculty of Medicine and Health, University of Sydney, NSW; Member, Doctors for the Environment Australia, Vic. I.Parise@westernsydney.edu.au

Competing interests: None.

Funding: None.

Provenance and peer review: Not commissioned, externally peer reviewed.

\section{References}

1. Institute for Health Metrics and Evaluation. Globa burden of disease comparison. Seattle, WA: Institute for Health Metrics and Evaluation, 2017. Available at https://vizhub.healthdata.org/gbdcompare/ [Accessed 4 December 2019].

2. Organisation for Economic Co-operation and Development. OECD obesity update 2017. Paris: OECD, 2017.

3. Australian Bureau of Statistics. National health survey: First results, 2017-18. Canberra: ABS, 2018. Available atwww.abs.gov.au/ausstats/abs@. nsf/PrimaryMainFeatures/4364.0.55.001?Open Document [Accessed 4 December 2019].

4. Brownell KD, Kersh R, Ludwig DS, et al. Personal responsibility and obesity: A constructive approach to a controversial issue. Health Aff (Millwood) 2010;29(3):379-87. doi: 10.1377/ hlthaff.2009.0739.

5. Bombak A. Obesity, health at every size, and public health policy. Am J Public Health 2014;104(2):e60-67. doi: 10.2105/ AJPH.2013.301486.

6. Todorovich J. The potential role of obesity bias among health professionals. JOPERD 2012;83(1):52. doi: 10.1080/07303084.2012.10598713.

7. Tomiyama AJ, Finch LE, Belsky AC, et al. Weight bias in 2001 versus 2013: Contradictory attitudes among obesity researchers and 
health professionals. Obesity (Silver Spring) 2015;23(1):46-53. doi: 10.1002/oby.20910.

8. Schwartz M, Chambliss $\mathrm{H}$, Brownell KD, Blair SN, Billington C. Weight bias among health professionals specializing in obesity. Obes Res 2003;11(9):1033-39. doi: 10.1038/oby.2003.142.

9. Pearce J, Witten K. Geographies of obesity: Environmental understandings of the obesity epidemic. Farnham, Surrey: Ashgate Publishing, 2010; p. 7.

10. Wilkinson R, Marmot M. Social determinants of health: The solid facts. 2 nd edn. Copenhagen: World Health Organization, 2003.

11. Australian Institute of Health and Welfare. Health and the environment: A compilation of evidence. Cat. no. PHE 136. Canberra: AlHW, 2011.

12. Australian Institute of Health and Welfare. Tobacco indicators: Measuring midpoint progress - Reporting under the National Tobacco Strategy 2012-2018. Drug statistics series no. 30. PHE 210. Canberra: AlHW, 2016.

13. Berrigan D, McKinno RA. Built environment and health. Prev Med 2008;47(3):239-40. doi: 10.1016/j.ypmed.2008.07.010.

14. Renalds A, Smith TH, Hale PJ. A systematic review of built environment and health. Fam Community Health 2010;33(1):68-78. doi: 10.1097/ FCH.0b013e3181c4e2e5.

15. Badland HM, Oliver M, Kearns RA, et al. Association of neighbourhood residence and preferences with the built environment, workrelated travel behaviours, and health implications for employed adults: Findings from the URBAN study. Soc Sci Med 2012;75(8):1469-76. doi: 10.1016/j.socscimed.2012.05.029.

16. Garfinkel-Castro A, Kim K, Hamidi S, Ewing R. Obesity and the built environment at different urban scales: Examining the literature. Nutr Rev 2017;75(Suppl 1):51-61. doi: 10.1093/nutrit/ nuw037.

17. Ewing R, Schmid T, Killingsworth R, Zlot A, Raudenbush $S$. Relationship between urban sprawl and physical activity, obesity, and morbidity. Am J Health Promot 2003;18(1):47-57. doi: 10.4278/0890-1171-18.1.47.

18. Ewing R, Meakins G, Hamidi S, Nelson AC. Relationship between urban sprawl and physical activity, obesity, and morbidity - Update and refinement. Health Place 2014;26:118-26. doi: 10.1016/j.healthplace.2013.12.008.

19. Kelly-Schwartz AC, Stockard JD, Doyle S, Schlossberg M. Is sprawl unhealthy?: A multilevel analysis of the relationship of metropolitan sprawl to the health of individuals. J Plan Educ Res 2004;24(2):184-96. doi: 10.1177/0739456X04267713.

20. Giles-Corti B, Macintyre S, Clarkson JP, Pikora T, Donovan RJ. Environmental and lifestyle factors associated with overweight and obesity in Perth, Australia. Am J Health Promot 2003;18(1):93-102. doi: 10.4278/0890-1171-18.1.93.

21. Epstein LH, Raja S, Daniel TO, et al. The built environment moderates effects of family-based childhood obesity treatment over 2 years. Ann Behav Med 2012;44(2):248-58. doi: 10.1007/ s12160-012-9383-4

22. Frank LD, Andresen MA, Schmid TL. Obesity relationships with community design, physical activity, and time spent in cars. Am J Prev Med 2004;27(2):87-96. doi: 10.1016/j. amepre.2004.04.011.

23. Lopez R. Urban sprawl and risk for being overweight or obese. Am J Public Health 2004;94(9):1574-79. doi: 10.2105/AJPH.94.9.1574.
24. Zhao Z, Kaestner R. Effects of urban sprawl on obesity. J Health Econ 2010;29(6):779-87. doi: 10.1016/j.jhealeco.2010.07.006.

25. Urhonen T, Lie A, Aamodt G. Associations between long commutes and subjective health complaints among railway workers in Norway. Prev Med Rep 2016;4:490-95. doi: 10.1016/j. pmedr.2016.09.001.

26. Hilbrecht M, Smale B, Mock SE. Highway to health? Commute time and well-being among Canadian adults. World Leis J 2014;56(2):151-63. doi: 10.1080/16078055.2014.903723.

27. Tajalli M, Hajbabaie A. On the relationships between commuting mode choice and public health. J Transp Health 2017;4:267-77. doi: 10.1016/j.jth.2016.12.007.

28. Langlois M, Wasfi RA, Ross NA, El-Geneidy AM. Can transit-oriented developments help achieve the recommended weekly level of physical activity? J Transp Health 2016;3(2):181-90. doi: 10.1016/j.jth.2016.02.006.

29. Christian TJ. Trade-offs between commuting time and health-related activities. J Urban Health 2012;89(5):746-57. doi: 10.1007/s11524-012-9678-6.

30. Hoehner CM, Barlow CE, Allen P, Schootman M. Commuting distance, cardiorespiratory fitness, and metabolic risk. Am J Prev Med 2012;42(6):571-78. doi: 10.1016/j. amepre.2012.02.020.

31. Sugiyama T, Niyonsenga T, Howard NJ, et al. Residential proximity to urban centres, local-area walkability and change in waist circumference among Australian adults. Prev Med 2016;93:39-45. doi: 10.1016/j.ypmed.2016.09.028.

32. Lopez-Zetina J, Lee H, Friis R. The link between obesity and the built environment. Evidence from an ecological analysis of obesity and vehicle miles of travel in California. Health Place 2006;12(4):656-64. doi: 10.1016/j. healthplace.2005.09.001.

33. Swanson KC, McCormack GR. The relations between driving behavior, physical activity and weight status among Canadian adults. J Phys Act Health 2012;9(3):352-59. doi: 10.1123/jpah.9.3.352

34. Wen LM, Orr N, Millett C, Rissel C. Driving to work and overweight and obesity: Findings from the 2003 New South Wales health survey, Australia. Int J Obes (Lond) 2006;30(5):782-86. doi: 10.1038/ sj.ijo.0803199.

35. Núñez-Córdoba JM, Bes-Rastrollo M, Pollack KM et al. Annual motor vehicle travel distance and incident obesity: A prospective cohort study. Am J Prev Med 2013;44(3):254-59. doi: 10.1016/j. amepre.2012.10.019.

36. Sugiyama T, Ding D, Owen N. Commuting by car: Weight gain among physically active adults. Am J Prev Med 2013;44(2):169-73. doi: 10.1016/j. amepre.2012.09.063.

37. Flint E, Webb E, Cummins S. Change in commute mode and body-mass index: Prospective, longitudinal evidence from UK Biobank. Lancet Public Health 2016;1(2):e46-e55. doi: 10.1016/ S2468-2667(16)30006-8.

38. Parra DC, Lobelo F, Gómez LF, et al. Household motor vehicle use and weight status among Colombian adults: Are we driving our way towards obesity? Prev Med 2009;49(2-3):179-83. doi: 10.1016/j.ypmed.2009.07.010.

39. Shoham DA, Dugas LR, Bovet $P$, et al. Association of car ownership and physical activity across the spectrum of human development: Modeling the Epidemiologic Transition Study (METS). BMC Public Health 2015;15:173. doi: 10.1186/s12889015-1435-9.
40. Laverty AA, Webb E, Vamos EP, Millett C. Associations of increases in public transport use with physical activity and adiposity in older adults. Int J Behav Nutr Phys Act 2018;15(1):31. doi: 10.1186/s12966-018-0660-x.

41. Lindström M. Means of transportation to work and overweight and obesity: A population-based study in southern Sweden. Prev Med 2008;46(1):22-28. doi: 10.1016/j.ypmed.2007.07.012.

42. Transportation Research Board and Institute of Medicine Does the Built Environment Influence Physical Activity?: Examining the Evidence Special Report 282. Washington, DC: The National Academies Press, 2005. doi: 10.17226/11203.

43. National Institute for Health and Care Excellence. Physical activity and the environment. London: NICE, 2018.

44. McCormack GR, Giles-Corti B, Bulsara M. The relationship between destination proximity, destination mix and physical activity behaviors. Prev Med 2008;46(1):33-40. doi: 10.1016/j. ypmed.2007.01.013.

45. Australian Institute of Health and Welfare. A picture of overweight and obesity in Australia 2017. Cat. no. PHE 216. Canberra: AlHW, 2017.

46. Keegan R, Middleton G, Henderson H, Girling M. Auditing the socio-environmental determinants of motivation towards physical activity or sedentariness in work-aged adults: A qualitative study. BMC Public Health 2016;16:438. doi: 10.1186/s12889-016-3098-6.

47. Badland $\mathrm{H}$, Whitzman $\mathrm{C}$, Lowe M, et al. Urban liveability: Emerging lessons from Australia for exploring the potential for indicators to measure the social determinants of health. Soc Sci Med 2014;111:64-73. doi: 10.1016/j. socscimed.2014.04.003.

48. Harrison M, Lee A, Findlay M, Nicholls R, Leonard D, Martin C. The increasing cost of healthy food. Aust N Z J Public Health 2010;34(2):179-86. doi: 10.1111/j.17536405.2010.00504.x.

49. Lovasi GS, Hutson MA, Guerra M, Neckerman KM. Built environments and obesity in disadvantaged populations. Epidemiol Rev 2009;31:7-20. doi: 10.1093/epirev/mxp005.

50. Li F, Harmer PA, Cardinal BJ, et al. Built environment, adiposity, and physical activity in adults aged 50-75. Am J Prev Med 2008;35(1):38-46. doi: 10.1016/j. amepre.2008.03.021. 